\title{
あるクラスの伝達関数を有する広義の平衡形 実現とその低感度性*
}

$$
\text { 岩月 正見 }{ }^{* *} \text { ・樋 口 龍 雄 }{ }^{* *}
$$

Balanced Realizations in the Wide Sense with a Class of Transfer Functions and Their Low Sensitivity*

Masami Iwatsuki ${ }^{* *}$ and Tatsuo Higuchi ${ }^{* *}$

This paper shows that balanced realizations in the wide sense have minimum statistical sensitivity and pole sensitivity, if the transfer functions have interlacing poles and zeros on the real axis of $z$-plane (i.r.p.z.). If the transfer functions have i.r.p.z., the balanced realizations in the wide sense can be easily obtained by computing the partial fraction expansion of the transfer functions. Since the state transition matrices of the obtained balanced realizations are diagonal, they can be implemented with much fewer parameters than balanced realizations with fully dense coefficient matrices.

\section{1. まえがき}

与えられた伝達関数を実現するための標準構造は, 従 来から数多く提案されている. てれらの様々な標準構造 は無限の精度で実現されるならば，まったく等価な入出 力特性を有している. しかし，パラメータの微小変動に よる入出力特性劣化の度合, すなわちシステム感度は実 現構造によって大きく異なる．実際にシステムを実現す る場合，希望の入出力特性からのずれは避けられないた め, このようなシステム感度は実現構造を評価する上で, 重要な尺度の一つとなる，著者らは，状態空間表現でき る線形システム一般に対する感度の評価基準の一つとし て, 統計的感度を提案し, Mooreにより提案された平 衡形実現 (balanced realization) が統計的感度を最小 にする構造の一つであることを明らかにした ${ }^{3}$. 平衡形 実現は，可制御性と可観測性の強さという測度に着目し た標準構造の一つであり, モデル低次数化に応用されて いる ${ }^{1,2}$. また, ディジタルフィルタの近似問題や丸め誤 差最小構造と密接な関係にあることが知られている ${ }^{4}$.

* 原稿受付 1987. 2. 24

** 東北大学 工学部 Faculty of Engineering, Tohoku University: Aramaki, Sendai 980, JAPAN

Key Words : balanced realization in the wide sense, interlacing real poles and zeros, statistical sensitivity, pole sensitivity, Cauchy index.
しかし，平衡形実現の合成アルゴリズムは，Lyapunov 方程式の解法や特異值分解などを必要とし, 計算が複雑 である．さらに平衡形実現の係数行列は完全に密である ため, パラメータ数が非常に多いという欠点がある.

本論文では. 伝達関数のすべての極と零点が実軸上に 交代して位置する時, 広義の平衡形実現が統計的感度と 極感度をともに最小化しているてとを明らかにする．ま たての場合，伝達関数の部分分数展開によって得られた パラメータを直接用いて, 広義の平衡形実現が極めて容 易に合成できることが示される.ささら得られた実現構 造の状態遷移行列は対角行列に選ぶことができるため, 係数行列が完全に密である平衡形実現と比較して, 非常 に少ないパラメータ数で実現できるという優れた特徴を 有する. 最後に計算例を用いて, 状態遷移行列が対角行 列である広義の平衡形実現が種々の感度に関して, 低感 度性を有することが示される。

\section{2. 広義の平衡形実現，統計的感度最小構造 および極感度最小構造}

\section{1 広義の平衡形実現}

$n$ 次の安定で厳密にプロパーな伝達関数 $H(z)$ が次の ように与えられたとする.

$$
H(z)=\frac{q_{1} z^{-1}+\cdots+q_{n} z^{-n}}{1+p_{1} z^{-1}+\cdots+p_{n} z^{-n}}
$$


この伝達関数 $H(z)$ を有する離散時間線形システムの状 態方程式は次式で表わされる.

$$
\begin{aligned}
& x(k+1)=A x(k)+b u(k) \\
& y(k)=c x(k)
\end{aligned}
$$

ここで, $x(k)$ は $n$ 次状態ベクトル, $u(k)$ と $y(k)$ はそ れぞれスカラの入力と出力であり， $A, b, c$ はそれぞれ $n \times n, n \times 1,1 \times n$ の実係数行列である. 乙れらの係数 行列を用いると，伝達関数は次のように表わされる.

$$
H(z)=c(z I-A)^{-1} b
$$

(2) 式で表わされるシステム $(A, b, c)$ が可制御かつ 可観測であるならば，次の Lyapunov 方程式

$$
\begin{aligned}
& K=A K A^{t}+b b^{t}=\sum_{i=0}^{\infty} A^{i} b b^{t} A^{i t} \\
& W=A^{t} W A+c^{t} c=\sum_{i=0}^{\infty} A^{i t} c^{t} c A^{i}
\end{aligned}
$$

の解 $K$ と $W$ は対称正定行列となる. $K$ と $W$ はそれぞ れシステム $(A, b, c)$ の可制御性グラミアン执よび可観 測性グラミアンと呼ばれている. それぞれのグラミアン の固有值の大きさが可制御性と可観測性の強さを定量的 に表わす尺度であり，次節で述べる統計的感度と密接な 関係がある ${ }^{3}$.

任意の $n \times n$ の正則行列 $T$ により, 状態ベクトルを $x^{\prime}(k)=T^{-1} x(k)$ と変換すると, 新しい状態ベクトルを 有するシステム $\left(A^{\prime}, b^{\prime} c^{\prime}\right)$ は

$$
A^{\prime}=T^{-1} A T, b^{\prime}=T^{-1} b, c^{\prime}=c T
$$

となる. 乙の時, システム $\left(A^{\prime}, b^{\prime}, c^{\prime}\right)$ の可制御性グラミ アン $K^{\prime}$ と可観測性グラミアン $W^{\prime}$ は次式のようになる.

$$
\begin{aligned}
& K^{\prime}=T^{-1} K T^{-t} \\
& W^{\prime}=T^{t} W T
\end{aligned}
$$

したがって， $K^{\prime}$ と $W^{\prime}$ の固有值は等価変換行列 $T$ によ り異なり, 状態空間の可制御性と可観測性の強さが変化 するととがわかる．また，積 $K^{\prime} W^{\prime}$ の固有值は，（6）式 から次のようになる.

$$
\begin{aligned}
K^{\prime} W^{\prime} & =\left(T^{-1} K T^{-t}\right)\left(T^{t} W T\right) \\
& =T^{-1} K W T
\end{aligned}
$$

したがって, 積 $K^{\prime} W^{\prime}$ の固有值は等価変換に対して不 変であることがわかる.

等価変換行列 $T$ を適当に選ふことにより, 次の定義 で示されるような平衡形実現が得られる ${ }^{1,2}$.

「定義 1 システム $\left(A_{b}, b_{b}, c_{b}\right)$ の可制御性グラミアン $K_{b}$ と可観測性グラミアン $W_{b}$ が, 関係式

$$
\begin{aligned}
K_{b} & =W_{b}=\Theta \\
& =\operatorname{diag}\left(\theta_{1}, \theta_{2}, \cdots, \theta_{n}\right) \\
\theta_{i} & =\left[\lambda_{i}(K W)\right]^{1 / 2}
\end{aligned}
$$

を満たす時, このシステムを平衡形実現という。ここで, $\lambda_{i}(X)$ は行列 $X$ の $i$ 番目の固有值を表わす.」

（8）式からわかるように, 状態空間の可制御性之可観 測性の強さが等しいてとから, システム $\left(A_{b}, b_{b}, c_{b}\right)$ は 平衡形実現と呼ばれる.

さらに, 上述の平衡形実現に対して, 状態空間の座 標軸に回転の自由度を加えたものを広義の平衡形実現 (balanced realization in the wide sense) と呼び, 次のように定義する ${ }^{5}$.

「定義 2 システム $\left(A_{w b}, b_{w b}, c_{w b}\right)$ の可制御性グラミア ン $K_{w b}$ と可観測性グラミアン $W_{w b}$ が, 関係式

$$
K_{w b}=W_{w b}=U^{t} \Theta U
$$

を満たす時，てのシステムを広義の平衡形実現と呼ぶ. ここで, $U$ は任意の直交行列である.」

(9) 式において, $U= \pm I$ ( $I$ : 単位行列) と置けば, 平衡形実現となることは容易にわかる.

\section{2 統計的感度最小構造}

システムパラメータの微小変動がどの程度出力に影響 を及ぼすかを知ることは，システム感度を評価する上で 重要である，したがって，本節では，乙のようなシステ ム感度の尺度の一つである統計的感度の定義を与え, 統 計的感度最小構造について述べる.

システム $(A, b, c)$ に対して, その係数行列がランダ ムに変動しているとして次の仮想システムを考える.

$$
\tilde{x}(k+1)=[A+\Delta A(k)] \widetilde{x}(k)+[b+\Delta b(k)] u(k)
$$

$$
\widetilde{y}(k)=[c+\Delta c(k)] \widetilde{x}(k)
$$

ここで, 係数行列の微小変動 $\Delta A(k), \Delta b(k), \Delta c(k)$ の 各要素は，互いに無相関であり，その平均を 0 , 分散を $\sigma^{2}(0<\sigma \ll 1)$ とする. 入力信号 $u(k)$ は, 平均 0 , 分 散 1 の正規白色過程と仮定する. 乙の時, 定常誤差

$$
E\left[\Delta y^{2}\right]=\lim _{k \rightarrow \infty} E\left[\{\widetilde{y}(k)-y(k)\}^{2}\right]
$$

が求められ，乙れを用いて統計的感度 $S$ を次式で定義 する.

$$
S=E\left[\Delta y^{2}\right] / \sigma^{2}
$$

上式で表わされる統計的感度 $S$ は，システムの可制御 性と可観測性の強さと密接に関連しており，その可制御 性グラミアンと可観測性グラミアンを用いて，次式で与 えられることが知られている3.

$$
S=\operatorname{tr}[K] \operatorname{tr}[W]+\operatorname{tr}[K]+\operatorname{tr}[W]
$$

上式は係数行列 $(A, b, c)$ による伝達関数 $H(z)$ の偏微 分のノルムで定義される係数感度の上限からも導出でき ることが知られている ${ }^{6}$ (4. (48) 式参照). 上式で表わ される統計的感度 $S$ に関して次の命題が成り立つ. 
「命題 1 システム $(A, b, c)$ が統計的感度最小構造であ るための必要十分条件は，その可制御性グラミアン $K$ と可観測性グラミアン $W$ が次の関係式を満たすととで ある.

$$
K=W=U^{t} \Theta U
$$

この時, 統計的感度 $S$ は最小値として,

$$
S_{\min }=\left(\sum_{i=1}^{n} \theta_{i}\right)^{2}+2 \sum_{i=1}^{n} \theta_{i}
$$

をとる.」

（証明）文献 3) 参照.

したがって, 定義 2 と命題 1 より, 統計的感度を最小 にする実現構造は広義の平衡形実現であることがわかる.

\section{3 極感度最小構造}

伝達関数の極は安定性, 入出力特性を決める上で重要 である. したがって, システムパラメータの微小変動が, 伝達関数の極によ゙の程度影響を及ぼすかを知ることは重 要である，本節では，乙のような尺度である極感度を定 義し, 極感度最小構造について述べる.

伝達関数の極は, 状態遷移行列 $A$ の固有值として求 められるから，極感度は次のように定義できる.

$$
S_{p}=\sum_{i=1}^{n} \operatorname{tr}\left\{\left[\frac{\partial \lambda_{i}(A)}{\partial A}\right]\left[\frac{\partial \lambda_{i}(A)}{\partial A}\right]^{*}\right\}
$$

ここで, *は共役転置を表わす. 上式で表わされる極感 度 $S_{p}$ に関して次の命題が成り立つ.

「命題 2 極感度 $S_{p}$ が最小となるための必要十分条件は, 状態遷移行列 $A$ が正規行列すなわち,

$$
A A^{t}=A^{t} A
$$

となることである. このとき, 極感度 $S_{p}$ は最小値とし $\tau$,

$$
S_{p \min }=n
$$

をとる.」

（証明）文献 7) 参照.

\section{3. あるクラスの伝達関数を有する広義の 平衡形実現}

本章では，伝達関数のすべての極と零点が実軸上で交 代して位置する時（以下，乙のような極零点配置を持つ ことを性質 i.r.p.z. (interlacing real poles and zeros）を満たすという.)，広義の平衡形実現は統計的 感度を最小にしているだけでなく，極感度をも最小にし ていることを明らかにする. さらにこの場合, 伝達関数 の部分分数展開係数を直接用いて, 広義の平衡形実現が 極めて容易に合成できることを示す。

\section{1 統計的感度と極感度の最小性}

まず, 以後の議論で必要となる Cauchy indexと対 称行列の符号について述べておく.

$\omega$ を実数とする時, 実有理関数 $F(\omega)$ の $a<\omega<b$ に打ける Cauchy index とは, $\omega$ が $a$ から $b$ へと変化 してゆくとき, $F(\omega)$ が-

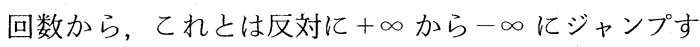
る回数を引いたものである. これを $I_{a}^{b} F(\omega)$ と書く ${ }^{11}$.

また, 正則な対称行列 $R$ の符号 $(p, q)$ は次のように 定義される.

$$
\left\{\begin{array}{l}
p=R \text { の正の固有値の数 } \\
q=R \text { の負の固有值の数 }
\end{array}\right.
$$

ここで, $p^{+} q=n$ である.

一般に, 上記の Cauchy index および対称行列の符 号とシステムの係数行列 $A, b, c$ には, 次の命題に示さ れるような関係が成り立つことが知られている。

「命題 3 システム $(A, b, c)$ に対して, 次式を満たすよ うなただ一つの対称行列が存在する.

$$
R A=A^{t} R, \quad R b=c^{t}
$$

また, 対称行列 $R$ の符号 $(p, q)$ の差 $p-q$ は伝達関数. の Cauchy index に等しい.」

（証明）文献 10）参照.

また，連続時間システムと同様に ${ }^{8}$, 離散時間システ ムに打いても平衡形実現の係数行列 $A_{b}, b_{b}, c_{b}$ には次の 定理に示されるような関係が成り立つ.

「定理 $1 \quad \theta_{1}>\cdots>\theta_{r+1}=\cdots=\theta_{r+s}>\cdots>\theta_{n}$ の時, 平 衡形実現の係数行列 $A_{b}, b_{b}, c_{b}$ は次式の関係を満たす。

$$
A_{b}^{t}=\Pi A_{b} \Pi, b_{b}=\Pi c_{b}^{t}
$$

ここで, 行列 $\Pi$ は次のように表わされる符号行列であ る.

$$
\begin{aligned}
& \Pi=\operatorname{block} \operatorname{diag}\left(\Pi_{1}, U_{s} \Pi_{2} U_{s}^{t}, \Pi_{3}\right) \\
& \Pi_{1}=\operatorname{diag}\left(\pi_{1}, \cdots, \pi_{r}\right) \\
& \Pi_{2}=\operatorname{diag}\left(\pi_{r+1}, \cdots, \pi_{r+s}\right) \\
& \Pi_{3}=\operatorname{diag}\left(\pi_{r+s+1}, \cdots, \pi_{n}\right) \\
& \pi_{i}= \pm 1 \quad(i=1,2, \cdots, n)
\end{aligned}
$$

また， $U_{s}$ は $s \times s$ の直交行列である.」

（証明）（4）式で与えられるLyapunov方程式に(8) 式を代入すると, 次式を得る.

$$
\begin{aligned}
& \Theta=A_{b} \Theta A_{b}^{t}+b_{b} b_{b}^{t} \\
& \Theta=A_{b}^{t} \Theta A_{b}+c_{b}^{t} c_{b}
\end{aligned}
$$

（22.1）式に（20）式を代入し, 両辺に両側加ら対称行 列 $R$ を加ると, 次式を得る.

$$
R \Theta R=A_{b}^{t}(R \Theta R) A_{b}+c_{b}^{t} c_{b}
$$


となる. 上式と (22.2) 式を比較すれば,

$$
\Theta=R \Theta R
$$

を得る. ここで, $R$ は対称行列であるから, 直交行列 $U$ と対角行列 $\Lambda_{R}$ を用いて, 次のように表わすことが できる.

$$
\begin{aligned}
& R=U \Lambda_{R} U^{t} \\
& \Lambda_{R}=\operatorname{diag}\left(\lambda_{R 1}, \lambda_{R 2}, \cdots, \lambda_{R n}\right)
\end{aligned}
$$

（25）式を(24）式に代入し, 両辺の左側から $U^{t}$, 右側 から $U$ をかけると次式を得る.

$$
P=\Lambda_{R} P \Lambda_{R}=U^{t} \Theta U
$$

行列 $P$ の第 $i$ 対角成分 $p_{i i}$ を書き表わすと,

$$
p_{i i}=\lambda_{R i}^{2} p_{i i}
$$

となり， $\lambda_{R i}= \pm 1$ を得る. したがって, 命題 3 と (25) 式から， $R$ は符号行列 $\Pi$ 之直交行列 $U$ を用いて次式 のように表わせる.

$$
R=U \Pi U^{t}
$$

したがって,

$$
R=R^{t}=R^{-1}
$$

を満たし，（24）式から，

$$
\Theta R=R \Theta
$$

を得る.（30) 式の第 $(i, j)$ 成分を書き表わすと,

$$
\theta_{i} r_{i j}=\theta_{j} r_{i j}
$$

となり, $\theta_{i} \neq \theta_{j}$ のとき,

$$
r_{i j}=0 \quad(i \neq j)
$$

を得る.したがって, $i \leqq r$ または $i \geqq r+s+1$ の時, (24) 式の第 $i$ 対角成分は

$$
\theta_{i}=\sum_{i=1}^{n} \theta_{j} r_{i j}^{2}=\theta_{i} r_{i i}^{2}
$$

となり, 次式を得る.

$$
r_{i i}= \pm 1
$$

（28）式，（32）式と（34）式から,

$$
R=\Pi=\text { block diag }\left(\Pi_{1}, U_{s} \Pi_{2} U_{s}^{t}, \Pi_{3}\right)
$$
を得る.

また一般に，（21）式を満たすシステムの可制御性グ ラミアンと可観測性グラミアンの関係について, 次の補 題が成り立つ.

「補題 1 システム $(A, b, c)$ が (21) 式を満たす時, そ の可制御性グラミアン $K$ と可観測性グラミアン $W$ に 次の関係式が成り立つ.

$$
K=\Pi W \Pi
$$

（証明）（4.2）式の Lyapunov 方程式に（21）式を代入
し，両辺に両側から符号行列 $\Pi$ をかけると，

$$
\begin{aligned}
\Pi W \Pi & =A \Pi W A \Pi+b b^{t} \\
& =A(\Pi W \Pi)(\Pi A \Pi)+b b^{t} \\
& =A(\Pi W \Pi) A^{t}+b b^{t}
\end{aligned}
$$

となる.上式と (4.1) 式を比較すれば,

$$
K=\Pi W \Pi
$$

を得る.

補題 1 から,（21）式を満たすシステムの可制御性グラ ミアン $K$ と可観測性グラミアン $W$ は対角要素が等し く，非対角要素は符号を除いて等しいてとがわかる.

さらに，符号行列 $\Pi$ に関して，次の補題が成り立 $\supset^{8,9}$.

「補題 2 符号行列 $\Pi$ が

$$
\Pi= \pm I
$$

となるための必要十分条件は, 伝達関数 $H(z)$ のすべ ての極と零点が実軸上で交代して位置するてとである.」 （証明） 伝達関数 $H(z)$ が性質 i.r.p.z. を満たす時, $H(z)$ は次式のように部分分数展開できる.

$$
H(z)=\sum_{i=1}^{n} \frac{\alpha_{i}}{z^{-} \lambda_{i}}
$$

ここで， $\alpha_{i}, \lambda_{i}$ は実数であり， $\alpha_{i}$ の符号はすべて+ある いはすべてーのよ゙ちらか一方である. 乙の時, Cauchy index は次のような值をとる11.

$$
I_{-\pi}^{+\pi} H\left(e^{j \omega}\right)=p^{-} q=\sum_{i=1}^{n} \operatorname{sgn}\left(\alpha_{\mathrm{i}}\right)=\left\{\begin{array}{c}
n \\
-n
\end{array}\right.
$$

したがって，符号行列 $\Pi$ の符号 $(p, q)$ は次のようにな る.

$$
(p, q)=\left\{\begin{array}{l}
(n, 0) \\
(0, n)
\end{array}\right.
$$

（21）式と上式より， $\Pi= \pm I$ を得る.

性質 i.r.p.z を満たす離散時間システムの極と零点が すべて正であるならば，そのシステムは低域通過形の傾 向を有し，すべて負であるならば，そのシステムは高域 通過形の傾向を有する. また, 正と負の極と零点が混在 するならば，そのシステムは帯域通過形の傾向を有する.

回路網理論の分野では, 連続時間システムに拈いてて のような性質 i.r.p.z.を満たす伝達関数は非振動のイ ンパルス応答を持ち， $R C$ あるいは $R L$ 回路で実現で きることが古くから知られている11.

伝達関数が性質 i.r.p.z.を満たす時，広義の平衡形 実現は次の定理で示されるような特徵的な性質を持つ。 「定理 2 伝達関数 $H(z)$ が性質 i.r.p.z. を満たす時, システム $\left(A_{w b}, b_{w b}, c_{w b}\right)$ が広義の平衡形実現となるた めの必要十分条件は, その係数行列が次のような関係式 
を満たすととである.

$$
A_{w b}^{t}=A_{w b}, \quad b_{w b}= \pm c_{w b}^{t}
$$

（証明）まず，十分性を証明する．伝達関数 $H(z)$ が 性質 i.r.p.z.を満たす時, (41) 式が成り立つならば, 補題 1 と補題 2 より

$$
K=\Pi W \Pi=( \pm I) W( \pm I)=W
$$

を得る。したがって,（41）式が成り立つ時, 広義の平 衡形実現となる.

次に必要性を証明する. 任意の直交行列 $U$ を等価変 換行列として, 平衡形実現 $\left(A_{b}, b_{b}, c_{b}\right)$ を広義の平衡形 実現 $\left(A_{w b}, b_{w b}, c_{w b}\right)$ 飞変換すると,

$$
A_{w b}=U^{t} A_{b} U, b_{w b}=U^{t} b_{b}, c_{w b}=c_{b} U
$$

となる. したがって, 定理 1 と補題 2 から, 平衡形実現 $\left(A_{b}, b_{b}, c_{b}\right)$ が (41) 式を満たすととは明らかであるか ら, 次式を得る.

$$
\begin{aligned}
& A_{w b}^{t}=U^{t} A_{b}^{t} U=U^{t} A_{b} U=A_{w b}, \\
& b_{w b}=U^{t} b_{b}=U^{t} c_{b}^{t}= \pm c_{w b}^{t}
\end{aligned}
$$

したがって, 広義の平衡形実現ならば,（41）式を満た す.

定理 2 は, 伝達関数が性質 i.r.p.z. を満たす時には, 可制御性グラミアンと可観測性グラミアンを経由するこ となく係数行列のみに着目すれば, 広義の平衡形実現が 得られるてとを表わしている.

さらにての場合，広義の平衡形実現に関して，次の定 理が成り立つ.

「定理 3 伝達関数 $H(z)$ が性質 i.r.p.z. を満たす時, 広義の平衡形実現は統計的感度最小構造かつ極感度最小 構造である.」

（証明）定義 2 の（9）式と命題 1 の（14）式が一致して いるととから, 統計的感度最小構造であるととは明らか である.

定理 2 の (41) 式から, 状態遷移行列 $A_{w b}$ は

$$
A_{w b}^{t} A_{w b}=A_{w b} A_{w b}^{t}
$$

を満たす。したがって, 命題 2 から, 伝達関数 $H(z)$ が性質 i.r.p.z.を満たす時, 広義の平衡形実現は極感 度最小構造となる。

\section{2 合成法}

定理 2 から, 伝達関数 $H(z)$ が性質 i.r.p.z. を満た す場合，(41）式が成り立つように係数行列を選べば, 広義の平衡形実現が得られることになる.したがって, まず, 状態遷移行列を最む簡単な対称行列の一つとして 対角行列に選ぶ.

性質 i.r.p.z. を満たす伝達関数 $H(z)$ は (38) 式のよ うに部分分数展開できる。したがって，上式に含まれる
パラメータ $\lambda_{i}$ を直接用いて, 状態遷移行列 $A_{w b}$ を次の ように対角行列に選ぶことができる.

$$
A_{w b}=\operatorname{diag}\left[\lambda_{1}, \lambda_{2}, \cdots, \lambda_{n}\right]
$$

(38) 式, (41) 式と (44) 式から, 係数行列 $b_{w b}$ と $c_{w b}$ は次式を満たさなければならない。

$$
\begin{aligned}
& b_{w b} c_{w b}=\operatorname{diag}\left[\alpha_{1}, \alpha_{2}, \cdots, \alpha_{n}\right] \\
& b_{w b}= \pm c_{w b}
\end{aligned}
$$

したがって, $b_{w b}$ と $c_{w b}$ を次のように選べばよい.

$$
\begin{aligned}
b_{w b}^{t} & =\left[\left|\alpha_{1}\right|^{1 / 2},\left|\alpha_{2}\right|^{1 / 2}, \cdots,\left|\alpha_{n}\right|^{1 / 2}\right] \\
c_{w b} & =\left[ \pm\left|\alpha_{1}\right|^{1 / 2}, \pm\left|\alpha_{2}\right|^{1 / 2}, \cdots, \pm\left|\alpha_{n}\right|^{1 / 2}\right]
\end{aligned}
$$

以上のととから, , 伝達関数が性質 i.r.p.z. を満たす 時, 伝達関数の部分分数展開係数を直接用いて, 極めて 容易に広義の平衡形実現が合成できるととがわかる.さ らに, 広義の平衡形実現のパラメー夕数は一般に $\left(n^{2}+\right.$ $2 n$ ) 個を必要とするのに対し，乙こで合成される広義 の平衡形実現の状態遷移行列は対角行列であるから, $3 n$ 個のパラメータ数しか必要としない. したがって, 係数 行列に含まれる 0 要素を不感であるとすれば, 更に低感 度な実現構造であるといえる。

バターワースやチェビシェつなどの標準的なディジタ ルフィル夕の極と零点は, 複素数であることが多く, て のようなディジタルフィルタでは, 一般に性質 i.r.p.z. を満たすことは少ない。しかし，大規模なシステムを実 現する場合, 性質 i.r.p.z. を満たす部分と満たさない 部分を分けて合成し，それらを並列接続あるいは縦続接 続すれば, 実現に要する計算量が減少され, かつ極めて 低感度な実現構造が得られると考えられる。

\section{4. 計算例}

次の 3 次の伝達関数 $H(z)$ を考える.

$$
H(z)=\frac{1.5216 z^{-1}-1.9642 z^{-2}+0.5934 z^{-3}}{1-1.8415 z^{-1}+1.0549 z^{-2}-0.1827 z^{-3}}
$$

上式で表わされる伝達関数 $H(z)$ は次のような極 $\lambda_{i}$ 之零点 $z_{i}$ を持つ.

$$
\begin{aligned}
& \lambda_{1}=0.3255 \\
& \lambda_{2}=0.6433 \\
& \lambda_{3}=0.8728 \\
& z_{1}=0.4822 \\
& z_{2}=0.8057
\end{aligned}
$$

したがって, この伝達関数 $H(z)$ は性質 i.r.p.z.を満 たす. また，(38）式の留数 $\alpha_{i}$ は次のようになる.

$$
\begin{aligned}
& \alpha_{1}=0.6626 \\
& \alpha_{2}=0.5558 \\
& \alpha_{3}=0.3031
\end{aligned}
$$


Table 1 Coefficient matrices, statistical sensitivity and pole-sensitivity

\begin{tabular}{|c|ccc|c|r|r|c|}
\hline Structure & \multicolumn{3}{|c|}{$A$} & $b$ & \multicolumn{1}{c|}{$c^{t}$} & $S$ & $S_{p}$ \\
\hline Controllability & 0.0 & 1.0 & 0.0 & 0.0 & 0.5934 & 1770.063 & 1177.909 \\
Canonical & 0.0 & 0.0 & 1.0 & 0.0 & -1.9642 & & \\
Realization & 0.1827 & -1.0549 & 1.8415 & 1.0 & 1.5216 & & \\
\hline Balanced & 0.6703 & -0.2055 & -4.1662 & 1.1854 & 1.1854 & 14.693 & 3.0 \\
Realization & -0.2055 & 0.6116 & -0.1688 & 0.3375 & 0.3375 & & \\
& -4.1662 & -0.1688 & 0.5596 & 0.0508 & 0.0508 & & \\
\hline Balanced & 0.3255 & 0.0 & 0.0 & 0.8140 & 0.8140 & 14.693 & 3.0 \\
Realization & 0.0 & 0.6433 & 0.0 & -0.7455 & -0.7455 & & \\
in the Wide Sense & 0.0 & 0.0 & 0.8728 & 0.5506 & 0.5506 & & \\
\hline
\end{tabular}

（47）式で与えられる伝達関数 $H(z)$ を有する可制御 標準形実現，平衡形実現㧍よび本論文で提案した広義 の平衡形実現の係数行列, 統計的感度打よび極感度を Table 1 亿示す. Table 1 から, 平衡形実現之広義の平 衡形実現が二つの感度をとあに最小化していることがわ かる. また，広義の平衡形実現の状態遷移行列は対角行 列となり，パラメータ数が少ないととがわかる。また， 次式で定義される周波数感度 $S_{f}(\omega)$

$$
\begin{aligned}
S_{f}(\omega)= & \operatorname{tr}\left\{\left[\frac{\partial H\left(e^{j \omega}\right)}{\partial A}\right]\left[\frac{\partial H\left(e^{j \omega}\right)}{\partial A}\right]^{*}\right. \\
& +\left[\frac{\partial H\left(e^{j \omega}\right)}{\partial b}\right]\left[\frac{\partial H\left(e^{j \omega}\right)}{\partial b}\right]^{*} \\
& \left.+\left[\frac{\partial H\left(e^{j \omega}\right)}{\partial c}\right]\left[\frac{\partial H\left(e^{j \omega}\right)}{\partial c}\right]^{*}\right\}
\end{aligned}
$$

について比較したものを Fig. 1 に示す. Fig.1から, 周波数感度に関しても, 平衡形実現と広義の平衡形実現 が非常に低感度であることがわかる。

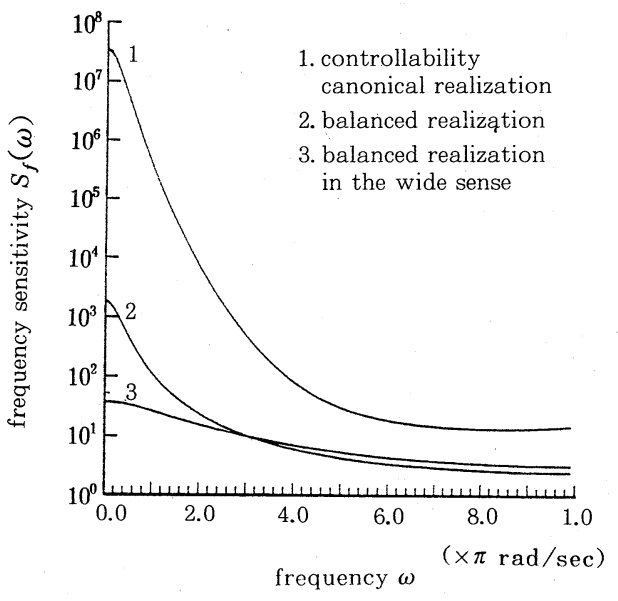

Fig. 1 Frequency sensitivity

\section{5.あとがき}

本論文では，伝達関数のすべての極と零点が実軸上で 交代する時, 広義の平衡形実現が統計的感度と極感度を ともに最小化しているてとを明らかにした．さらにての 場合, 広義の平衡形実現の一つが伝達関数の部分分数展 開係数から極めて容易に合成できるてとが示された。 ま た, 得られた実現構造の状態遷移行列が対角行列に選心 ることから, 係数行列が完全に密である平衡形実現と比 較して，少ないパラメータ数で合成できることも示され た.

しかし，本論文では，伝達関数のすべての極と零点が 害軸上で交代する時のみに関して, 広義の平衡形実現が 非常に優れた性質を持つことを述べたに過ぎない，一般 の場合については, 今後の課題としたい.

最後に 日頃から 熱心に 御討論いただいた 本学工学部 川又政征助教授に感謝いたします。

\section{参 考 文 献}

1) B. C. Moore : Principal Component Analysis in Linear Systems : Controllability, Observa-bility and Model Reduction ; IEEE Trans. Automat. Contr., Vol. AC-26, No. 1, pp. 17 32 (1981)

2) L. Pernebo \& L. M. Silverman : Model Reduction via Balanced State Space Representations ; IEEE Trans. Automat. Contr., Vol. AC-27, No. 2, pp. 382 387 (1982)

3) 川又, 岩月, 樋口: 線形システムにおける感度最小構造と しての平衡形実現; 計測自動制御学会論文集, Vol. 21, No. 9, pp. 900 906 (1986)

4) 川又, 樋ロ: ディジタルフィルタと線形システム理論 ; シ ステムと制御, Vol. 31,No. 5, pp. 325〜332 (1987)

5) S. Shokoohi : Block-Balanced Realizations ; IEEE Int. Symp. Circuits Syst. Proc. Montreal, pp. 825 829 (1984)

6) V. Tavsanoğlu \& L. Theile : Optimal Design of StateSpace Digital Filters by Simultaneous Minimization of Sensitivity and Round-off Noise ; IEEE Trans. Circuits Syst., Vol. CAS-31, No. 10, pp. 884 888 (1984)

7) R. E. Skelton \& D. A. Wagie : Minimal Root Sensi- 
tivity in Linear Systems ; Journal of Guidance, Control, and Dynamics, Vol. 7, No. 5, pp. 570 574 (1984)

8) E. A. Jonckheere : Principal Component Analysis of Flexible Systems--Open Loop Case ; IEEE Trans. Automat. Contr., Vol. AC-29, No. 12, pp. 1095 1097 (1984)

9) R.W. Brockett : Some Geometric Questions in the Theory of Linear Systems ; IEEE Trans. Automat. Contr., Vol. AC-21, No. 4, pp. 449 455 (1976)

10) K. V. Fernando \& H. Nicholson : On the Cauchy Index of Linear Systems ; IEEE Trans. Automat. Contr., Vol. AC-28, No. 2, pp. 222 224 (1983)

11) 高橋, 有本 : 回路網とシステム理論 ; コロナ社 (1974)

12）岩月, 樋口: あるクラスの伝達関数を有する平衡形実現と その極零点配置; 第 29 回自動制御連合講演会前刷, 1086, pp. 197〜198 (1986)

13) 岩月, 樋口: 線形システムにおける符号付平衡形実現と極 感度最小構造; 電子情報通信学会創立 70 周年記念総合全 国大会講演論文集, 1-1 (1987) 